\title{
Immunogenic tumor cell death induced by chemoradiotherapy: molecular mechanisms and a clinical translation
}

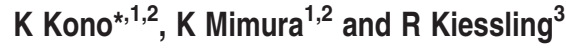

Chemoradiotherapy can induce immunogenic cell death, triggering danger signals such as high-mobility group box 1 protein, and resulting in T-cell immunity. This concept can potentially be harnessed for clinical therapy to enhance tumor-specific immunity. There is however limited information to translate this theory directly in a clinical setting. In this review, we will discuss and summarize molecular and cellular mechanisms underlying immunogenic tumor cell death induced by chemoradiotherapy, with emphasis on a clinical translation.

Cell Death and Disease (2013) 4, e688; doi:10.1038/cddis.2013.207; published online 20 June 2013

Subject Category: Cancer

Facts

- Immunogenic tumor cell death can elicit uptake of antigenic components by dendritic cells (DCs) and provide antigenic signals to $T$ cells, resulting in the expansion of antigen-specific cytotoxic $T$ lymphocytes (CTLs) and production of tumor-specific mAbs in murine models.

- Chemotherapy and radiotherapy induce danger signals such as high-mobility group box 1 (HMGB1) protein and immunogenic tumor cell death, which have an important role in harmonizing innate and acquired antitumor immunity.

- Chemoradiation induces tumor antigen-specific T-cell responses in clinical settings, which have the capability of modulating the clinical outcome of malignant diseases.

- Chemoradiotherapy can alter the frequency and function of immune regulatory cells including regulatory $T$ cells $\left(T_{\text {regs }}\right)$ and myeloid-derived suppressor cells (MDSC).

\section{Open Questions}

- What are the specifics of the processes involved in immunogenic tumor cell death in a clinical setting?

- Does HMGB1/toll-like receptor (TLR)4 interaction alone have a role in immunogenic tumor cell death?

- Can we predict clinical responses after radiotherapy or chemotherapy based on immunogenic tumor cell-death theory by measuring serum HMGB1 levels?

\section{Introduction}

It is well established that certain solid tumors respond clinically to radiotherapy, chemotherapy or combinations thereof, which prolong patient survival. ${ }^{1,2}$ It is also generally accepted that radiation is able to directly induce apoptosis or necrosis of solid tumors and various strategies have been developed to enhance direct cytotoxic and cytostatic effects through radiotherapy. ${ }^{3,4} \mathrm{~A}$ widely recognized, albeit rare phenomenon in clinical radiation oncology is called the abscopal effect, ${ }^{5-8}$ in which local radiotherapy causes regression of metastatic cancer at a distance from the irradiated site. The mechanisms underlying this phenomenon are not completely understood.

Recently, there is accumulating evidence to support the novel concept that radiotherapy and/or chemotherapy may induce immunogenic cell death and trigger uptake of antigenic components by DCs, which stimulate antigen-specific CTLs and production of tumor-specific mAbs in murine models. ${ }^{9-18}$ It has been shown that the nexus between the direct effects of irradiation and enhanced tumor-specific immunity induced by the irradiation are essential for rejection of inoculated live tumors, where irradiation alone was not able to reject tumors in murine models. ${ }^{9,10}$ Important mediators that induce immunogenic cell death include HMGB1, calreticulin and fragments of polynucleotides induced by chemoradiation. ${ }^{9-18}$

However, there is limited information describing whether immunogenic cell death could be induced by radiotherapy or/and chemotherapy in clinical settings, mainly because of

\footnotetext{
${ }^{1}$ Department of Surgery, National University of Singapore, Singapore; ${ }^{2}$ Cancer Science Institute of Singapore, Singapore and ${ }^{3}$ Department of Oncology and Pathology, Immune and Gene Therapy Laboratory, Cancer Center Karolinska, Karolinska Institutet, Stockholm, Sweden

${ }^{*}$ Corresponding author: K Kono, Department of Surgery, National University of Singapore, Level 8, NUHS Tower Block, 1E Kent Ridge Road, Singapore 119228, Singapore. Tel: + 656772 3196; Fax: + 656777 8427; Email: surkoji@nus.edu.sg

Keywords: HMGB1; calreticulin; immunogenic cell death; chemoradiation; cancer-testis antigen; TIM-3

Abbreviations: HMGB1, high-mobility group box 1; TLR, toll-like receptor; DCs, dendritic cells; CTLs, cytotoxic T lymphocytes; $T_{\text {regs, }}$ regulatory T cells; ROS, reactive oxygen species; MDSC, myeloid-derived suppressor cells; ESCC, esophageal squamous cell carcinoma; TIM-3, T-cell immunoglobulin- and mucin-domain-containing molecule

Received 09.4.13; revised 30.4.13; accepted 16.5.13; Edited by M Piacentini
} 
the lack of accurate assay systems to evaluate antigenspecific $\mathrm{T}$-cell responses in cancer patients receiving chemoradiotherapy. In this review, we will discuss immunogenic tumor cell death induced by chemoradiotherapy, with a particular focus on molecular mechanisms and a clinical setting.

\section{The Abscopal Effect in Radiation Oncology}

For decades, external beam irradiation has been utilized as loco-regional therapy for cancer and one of the adverse effects is suppression of systemic $T$ cell- and NK cellmediated immunity. However, radiation oncologists realized that there was a rare phenomenon called the 'abscopal effect' where local irradiation of a particular tumor site caused regression of metastases at sites distant from the irradiated area. ${ }^{5}$ This phenomenon was originally described by Dr. RJ Mole in 1953 who coined the name from Latin $a b$ (position away from) and scopus (mark or target). The abscopal effect has been shown in several types of malignant tumors, including melanoma, lymphoma, hepatocellular carcinoma and renal cell carcinoma. ${ }^{6-8,19}$ As an example of the abscopal effect, we have shown a patient with lymphoma who developed the abscopal effect after receiving radiation (Figure 1). Although the underlying mechanisms of the abscopal effect have not been completely understood, radiation oncologists speculated that activation of antitumor immunity in response to irradiation might be one of the mechanisms of to the abscopal effect. ${ }^{20,21}$ Postow et al. ${ }^{22}$ recently reported a case of the abscopal effect in a patient with melanoma treated with ipilimimab and radiotherapy, where tumor shrinkage was accompanied with antibody responses to the cancer-testis antigen NY-ESO-1 and changes in peripheral blood immune cells after radiotherapy. On the basis of the patient's unforeseen systemic response after local radiotherapy in combination with ipilimimab, they have conducted prospective clinical trials with this combination approach (ipilimimab and radiotherapy) in prostate cancer (NCT00861614) and melanoma (NCT01449279).

\section{Chemoradiotherapy can Induce Alterations in Immune Regulatory Cells}

In addition to the direct radiation-induced genetic damage and enhanced cross-presentation of tumor antigens, radiation can also affect immune regulatory circuits. There is evidence for radiation-induced modulation of effector versus CD4+ $\mathrm{CD} 25+\mathrm{T}_{\text {regs }}$ ratios, ${ }^{23}$ and this may have protracted and profound effects on the composition and function of T-cell populations. The mechanism behind this is unknown, but may involve a differential sensitivity of these T-cell subsets to radiation-induced reactive oxygen species (ROS). This view is compatible with our observation that $\mathrm{T}_{\text {regs }}$ are more resistant to ROS-induced cell death as compared with T effectors, and $T_{\text {regs }}$ maintain their suppressive function under conditions of high oxidative stress including radiation exposure. ${ }^{24}$ The molecular mechanism behind this resistance of $T_{\text {regs }}$ to oxidative stress may be related to the finding that human $T_{\text {regs }}$ express and secrete higher levels of thioredoxin-1, a major antioxidative molecule. ${ }^{25}$ Radiation-induced immune

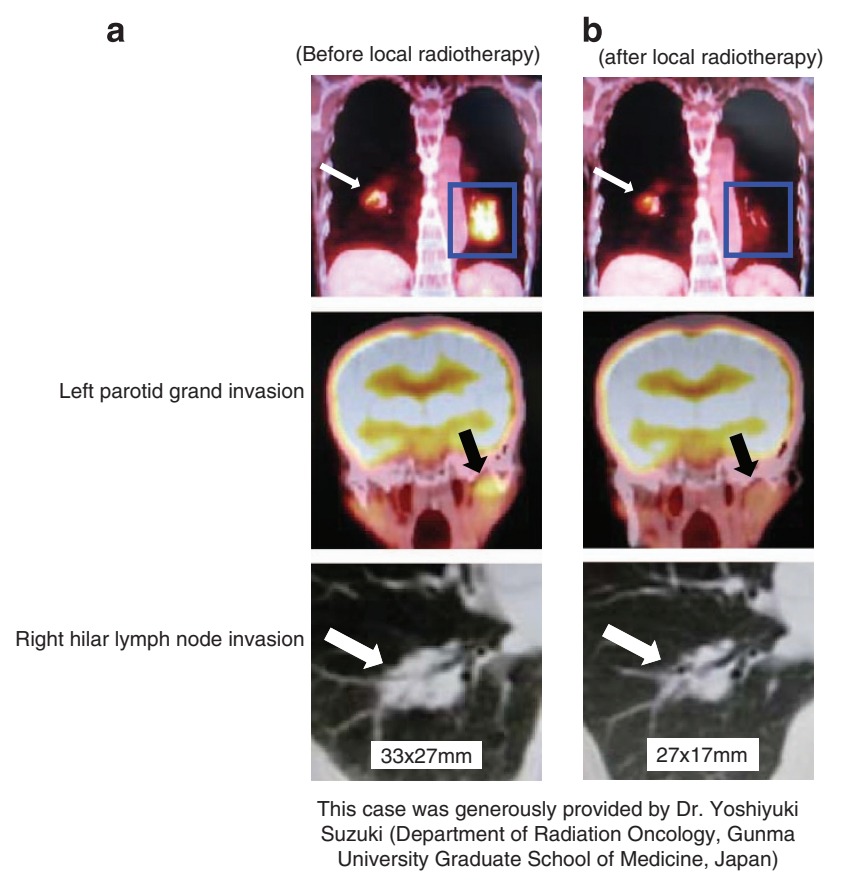

Figure 1 The abscopal effect in a relapsed lymphoma patient. An 81-year-old female had a relapsed lymphoma. Radiation therapy (total of 30.6 Gy in 17 fractions) was administered to the left hilar lymph node lesion (blue square). FDG-PET images (top and middle in panel $\mathbf{a}$ and $\mathbf{b}$ ) and axial CT images (bottom in panel $\mathbf{a}$ and $\mathbf{b}$ ) are shown. Blue squares indicate the irradiated field to the left hilar lymph node invasion; black arrows indicate the left parotid gland invasion (middle in panel $\mathbf{a}$ and $\mathbf{b}$ ) and white arrows indicate the right hilar lymph node invasion (bottom in panel $\mathbf{a}$ and $\mathbf{b}$ ). Panel a shows images before local radiotherapy. In panel $\mathbf{b}$ showing images at 8 months after local radiotherapy, the radiation-targeted left hilar lymphadenopathy and abnormal accumulation of FDG was disappeared (top). Furthermore, disease response outside of the irradiated field was seen with decreased left parotid gland (middle) and right hilar lymph node invasion (top and bottom)

suppression could therefore, at least in part, be explained by preferential induction of apoptosis in T-effector cells by ROS and sparing of $\mathrm{T}_{\text {regs }}$ through a thioredoxin-dependent mechanism.

Another immune suppressive factor to consider when discussing the effect of chemoradiotherapy on the immune system is the MDSC. They are a heterogenous population of myeloid cells with suppressive activity, containing precursors of granulocytes, macrophages and DCs. ${ }^{26}$ Circulating MDSC levels are increased in the blood of patients with several types of cancer and can induce profound suppression of T-cell and NK-cell functions. Several chemotherapeutic agents such as gemcitabine and 5-fluorouracil can downregulate MDSC frequencies ${ }^{27,28}$ and may therefore add to their clinical efficacy. One of the potential means of chemoradiotherapyinduced immune modulation may therefore occur through the effect on MDSC.

\section{Tumor Antigen-Specific T-Cell Response Induced By Chemoradiotherapy}

With the panel of HLA-A-restricted epitopes identified by us, ${ }^{29-32}$ we have established a reliable in vitro assay system using PBLs to detect tumor-specific CTL responses against 
these cancer-testis antigens. ${ }^{29-31}$ Using this assay, we examined tumor antigen-specific CTL responses in esophageal squamous cell carcinoma (ESCC) patients receiving chemoradiotherapy. In this study, tumor antigen-specific T-cell responses were confirmed in $6(38 \%)$ out of 16 ESCC patients following chemoradiotherapy. ${ }^{32}$ Furthermore, the level of HMGB1 following chemoradiation in the patients with antigen-specific T-cell responses was significantly elevated in comparison with that in the patients without antigen-specific T-cell responses. ${ }^{32}$ These results indicate that chemoradiation could induce tumor antigen-specific T-cell responses in a clinical setting, which correlated to HMGB1 levels (Figure 2). These results are analogous to the observations in several mouse models.

\section{HMGB1/TLR4}

HMGB1 is a chromatin-binding protein that acts as a transcription factor when present in the nucleus, as well as a proinflammatory cytokine, when released extracellularly from inflammatory or dying cells. ${ }^{33}$ HMGB1 is primarily released from damaged and necrotic cells, but it has been recently reported that late apoptosis is also associated with HMGB1 release. ${ }^{34}$ Importantly, anticancer treatments such as irradiation, anthracyclines and oxaliplatin induce HMGB1 release into the extracellular milieu by dying tumor cells. ${ }^{9-15}$ Once HMGB1 is released extracellularly, it binds to its receptor, TLR4, which is mainly expressed on DCs. HMGB1 has the ability to promote DC activation and trigger human DC migration in vitro. ${ }^{35-38}$ Subsequently, signaling through TLR4 and its adaptor MyD88 controls the initiation phase of cognate immune responses by regulating the processing of the phagocytosis and the cross-presentation of tumor antigens by DCs on MHC class I and class II molecules. ${ }^{10}$ HMGB1 released from tumor cells after chemotherapy enhances engulfment of antigenic components by DCs through TRL4 and mediates cross-presentation of tumor antigens into CD4 and CD8 T cells in several murine models. $^{9-15}$

In the clinical setting, we have shown that upregulation of HMGB1 within tumor microenvironment was significantly

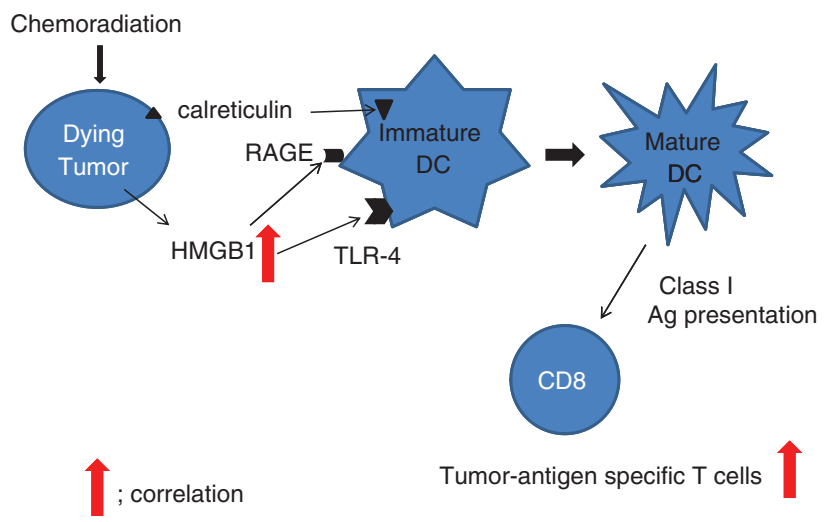

Figure 2 Schematic representations of tumor antigen-specific T-cell responses in patients with ESCC receiving chemoradiotherapy. HMGB1, high-mobility group box 1 protein related to preoperative chemoradiotherapy and higher levels of local HMGB1 correlated with increased patient survival. ${ }^{32}$ Moreover, tumor antigen-specific T-cell responses positively correlated with HMGB1 production. ${ }^{32}$ In addition, Apetoh et al. ${ }^{10}$ examined TLR4 loss-of-function allele in breast cancer patients, where polymorphism rs4986790 was found to reduce the binding of HMGB1 to TLR4. They reported that patients with TLR4 loss-of-function allele relapsed earlier after chemotherapy and radiotherapy than those with a highbinding TLR4 allele. These observations suggest a clinically relevant immune synapse between HMGB1 and TLR4. Thus, HMGB1-related immune response after chemoradiotherapy may have an important and critical role in clinical outcome of cancer treatments.

Paradoxically, it has been reported that an increased serum level of HMGB1 could predict tumor growth and invasiveness in several types of human cancer, in which elevated serum HMGB1 was linked with poor prognosis of cancer patients. ${ }^{39,40,41}$ It is likely that serum HMGB1 in these patients resulted from a systemic inflammatory response rather than the tumor microenvironment, as described above. We proposed that HMGB1 has two aspects on its action: systemic responses related to inflammatory reactions and local roles such as tumor microenvironment (Table 1, Figure 2). ${ }^{42-46}$

HMGB1 is also known to promote regulatory T-cell activity in cancer-bearing hosts, leading to the progression of preneoplastic lesions to cancer. ${ }^{47,48}$ Furthermore, HMGB1 is reported to activate TLR4- and RAGE-signaling pathways to induce caspase-1 activation with the subsequent production of multiple inflammatory mediators, which in turn promote cancer invasion and metastasis. ${ }^{49}$

Thus, HMGB1-TLR4 interaction appears to be Janus-like in its activity, stimulating immune responses to the detriment

Table 1 Reports on the relationship between HMGB1 status and patients' prognosis

\begin{tabular}{|c|c|c|c|}
\hline $\begin{array}{l}\text { HMGB1 } \\
\text { evaluation }\end{array}$ & Clinical significance & Cancer & References \\
\hline \multicolumn{4}{|c|}{ Positive correlation } \\
\hline $\begin{array}{l}\text { Local HMGB1 } \\
\text { (IHC) }\end{array}$ & $\begin{array}{l}\text { Patient survival, } \\
\text { response to CRT }\end{array}$ & ESCC & 32 \\
\hline $\begin{array}{l}\text { TLR4 } \\
\text { polymorphism }\end{array}$ & $\begin{array}{l}\text { Survival after } \\
\text { chemoradiotherapy }\end{array}$ & Breast & 10 \\
\hline \multicolumn{4}{|l|}{ Inverse correlation } \\
\hline $\begin{array}{l}\text { Serum HMGB1 } \\
\text { (ELISA) }\end{array}$ & Patient survival & Gastric & 39 \\
\hline $\begin{array}{l}\text { Serum HMGB1 } \\
\text { (ELISA) }\end{array}$ & $\begin{array}{l}\text { Response to } \\
\text { chemoembolization }\end{array}$ & $\begin{array}{l}\text { Liver } \\
\text { metastasis }\end{array}$ & 42 \\
\hline $\begin{array}{l}\text { Serum HMGB1 } \\
\text { (ELISA) }\end{array}$ & Patient survival & Pancreas & 43 \\
\hline $\begin{array}{l}\text { Local HMGB1 } \\
\text { (qPCR) }\end{array}$ & Patient survival & Colon & 44 \\
\hline $\begin{array}{l}\text { Local HMGB1 } \\
\text { (IHC) }\end{array}$ & Patient survival & Head/neck & 45 \\
\hline \multicolumn{4}{|c|}{ Not significant correlation } \\
\hline $\begin{array}{l}\text { Serum } \\
\text { HMGB1(ELISA) }\end{array}$ & Patient survival & Colon & 46 \\
\hline
\end{tabular}

Abbreviations: CRT, chemoradiotherapy; ESCC, esophageal squamous cell carcinoma; HMGB1, high-mobility group box 1 protein; IHC, immunohistochemistry; qPCR, quantitative PCR 
of the tumor or conversely aiding and abetting the growth of the tumor, as summarized in Table 1. The specific context or precise mechanisms by which the opposing effects are prompted remain unelucidated.

\section{Calreticulin}

Calreticulin predominantly reside within the lumen of the endoplasmic reticulum where they act as $\mathrm{a} \mathrm{Ca}^{+2}$-binding lectin chaperone. ${ }^{50,51}$ Premature exposure of calreticulin on the membrane following radiation enhances phagocytosis of dying tumor cells by DCs in vitro. ${ }^{15,52,53}$ Calreticulin is related to autophagy-dependent anticancer immune responses induced by chemotherapeutic agents. ${ }^{54}$ Once exposed on the membrane, the calreticulin/ERp57 complex provides a 'devour me' signal promoting uptake by DC of dying tumor cells. ${ }^{52,55}$

It has been shown that both HMGB1 release and calreticulin cell surface expression are required for antigen-specific T-cell response in a murine tumor-bearing model. ${ }^{52}$ However, we did not observe any significant differences in calreticulin expression between patients with and without chemoradiation, and there was no survival difference between calreticulinstrong and -weak groups. Moreover, the grade of infiltrating CD8 $(+)$ T cells within tumor microenvironment did not differ between calreticulin-strong and -weak groups. ${ }^{32}$ There is thus a discrepancy between the murine model and clinical setting in terms of significance of calreticulin expression in relation to T-cell immunity or chemoradiotherapy. Kroemer and Zitvogel ${ }^{17}$ previously reported that membrane expression of calreticulin was more relevant than global intracellular expression when immunogenic tumor cell death occurred in the murine model. ${ }^{52}$ Further investigation with different methodologies to measure the cell surface expression of calreticulin in clinical samples may resolve the paradox observed between the murine and human studies. Also, more accurate and detailed evaluations of calreticulin in clinical samples provide us with vital information including correlations with survival and a possible predictive marker of clinical effects.

\section{TIM-3 And HMGB1 on Tumor-Infiltrating DCs}

A recent study described by Chiba et al. ${ }^{56}$ adds more complexity into the immunogenic cell-death concept by proposing the involvement of T-cell immunoglobulin- and mucin-domain-containing molecule (TIM-3). ${ }^{56-58}$ TIM-3 was first identified as a receptor expressed by T-helper type 1 cells and interaction between TIM-3 and its ligand, galectin-9 provides an inhibitory signal that leads to apoptosis of T-helper type 1 cells. ${ }^{59-61}$ Chiba et al. ${ }^{56}$ reported that tumorinfiltrating DCs expressed higher level of TIM-3 than conventional DCs, and tumor-infiltrating DCs suppressed antitumor immune responses through TIM-3-mediated negative regulation of nucleic acid-dependent innate immunity. ${ }^{56}$ In general, the interaction between galectin- 9 and TIM-3 on antigenpresenting cells has an activating role in DC maturation and the cross-priming of tumor-specific $T$ cells. ${ }^{62,63}$ In contrast, TIM-3 on tumor-infiltrating DCs has an inhibitory effect for nucleic acid-mediated innate immune responses via a galectin-9-independent but HMGB1-dependent mechanism. ${ }^{56}$ Chiba et al. ${ }^{56}$ proposed that TIM-3 on DCs within tumor microenvironment having impaired induction of galectin-9 and high expression of HMGB1 may suppress innate immune responses by interfering with HMGB1TLR4-mediated stimulation (Figure 3). It is possible that the balance between a positive signal through HMGB1/TLR4 and a negative signal through HMGB1/TIM-3 might regulate the tumor antigen-specific T-cell responses within tumor microenvironment. More detailed evaluations in clinical samples are desirable and inevitable in order to draw a solid conclusion.

\section{Clinical Relevance Regarding to Immunogenic Tumor Cell Death}

Chemoradiotherapy is generally thought to be immunosuppressive, either by depleting T- and NK-cells or by rendering them functionally inactive. Systemic immunity in patients receiving chemoradiotherapy is often severely impaired, leading to infectious complications and growth of residual tumors. $^{64,65}$ Most chemotherapeutic drugs or radiotherapy mediate their cytotoxic effects by the induction of apoptosis, which is generally considered to be noninflammatory and nonimmunogenic. ${ }^{66,67}$ However, it has been proposed that danger signals released by dying cells following chemoradiotherapy could induce HMGB1/TLR4-dependent, antigen-specific T-cell immunity in a clinical setting, as shown in Figures 2 and 3.

Of interest, we showed that chemoradiation could induce upregulation of local HMGB1 with significant variations among ESCC patients (Figure 2), and patients with high HMGB1 expression had better OS than patients with weak HMGB1 expression. ${ }^{32}$ Also, the in vitro study indicated that there were substantial variations in HMGB1 production following chemoradiation depending on ESCC cell lines regardless of almost the same amount of dying cells. ${ }^{32}$ These observations suggest that immune reactions related to HMGB1 production following chemoradiation may affect clinical outcomes in ESCC patients.

Although cancer patients with solid tumor including the esophageal, rectal, lung and gastric cancers are clinically

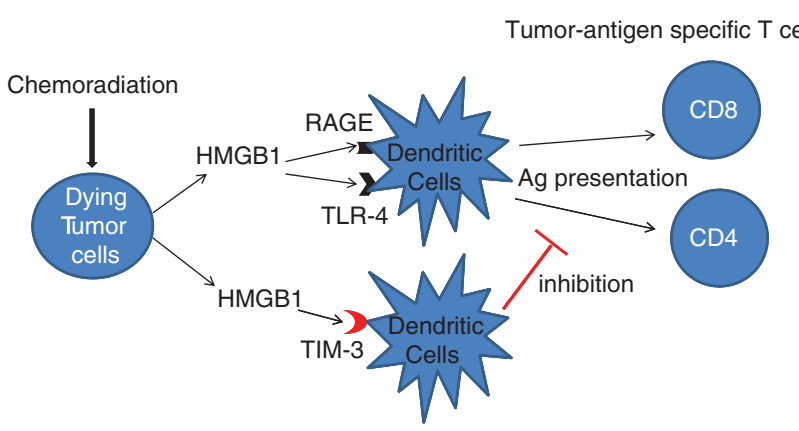

Figure 3 Schematic representations of possible molecular machineries whereby TIM-3 on tumor-infiltrating DCs negatively regulate innate immune signals that would be activated by HMGB1-TLR4 interaction. HMGB1, high-mobility group box 1 protein; TIM-3, T-cell immunoglobulin- and mucin-domain-containing molecule; TLR, toll-like receptor 
treated with chemoradiotherapy, it is well known that the clinical benefits vary considerably, with some good and some poorly responsive patients. For poor responders, the therapeutic benefits are often dubious and side effects can be considerable. If the precise mechanisms underlying immunogenic cell death induced by chemoradiotherapy were defined, there would potentially be two clinical applications. One would be prognostic, that is, to foretell the extent of benefit of chemoradiotherapy by measuring surrogate markers such as HMGB1, calreticulin, TIM-3 or galectin-9. The other application would be for treatment, that is, to enhance the therapeutic benefit of the chemoradiotherapy by sequentially combining it with cancer vaccine and other immune-activating therapies in patients with the biomarker profile of potential good responders. As the cancer-testis antigens have been identified and used for clinical trials in a variety of cancer, it is highly desirable to develop the therapeutic combination of chemoradiotherapy with cancer vaccine using the cancer-testis antigens.

\section{Conclusion and Perspectives}

At present, immunogenic tumor cell death is not explained merely by the HMGB1/TLR4-dependent pathway alone, and clinical outcome after the treatment is not predicted by serum levels of HMGB1. ${ }^{68,69}$ However, a better understanding of the molecular and cellular mechanisms underlying the chemoradiotherapy-induced immunogenic tumor cell death may help develop critical algorithms for the management of cancer patients. For example, we will be able to categorize the anticancer treatments that do or do not mediate an immunogenic cell-death pathway. Alternatively, we will be able to predict an optimal response to chemoradiotherapy based on danger signal-related molecules. Finally, we will be able to select the best adjuvants synergizing with immunogenic chemoradiotherapy. A novel approach based on immunogenic cell-death concept is presently being investigated in prospective clinical trials in prostate cancer and melanoma, testing a combination of local irradiation with ipilimimab.

Furthermore, it is desirable to establish crucial mice models in order to elucidate molecular and cellular mechanisms underlying the immunogenic tumor cell death and evaluate a significance of immunotherapy.

\section{Conflict of Interest}

The authors declare no conflict of interest.

Acknowledgements. We are grateful to Dr. Aniruddha Choudhury for critical reading of the article.

1. Ishikura S, Nihei K, Ohtsu A, Boku N, Hironaka S, Mera K et al. Long-term toxicity after definitive chemoradiotherapy for squamous cell carcinoma of the thoracic esophagus. J Clin Oncol 2003; 21: 2697-2702.

2. de Manzoni G, Pedrazzani C, Laterza E, Pasini F, Grandinetti A, Bernini M et al. Induction chemoradiotherapy for squamous cell carcinoma of the thoracic esophagus: impact of increased dosage on long-term results. Ann Thorac Surg 2005; 80: 1176-1183.

3. Polischouk AG, Grenman R, Granath F, Lewensohn R. Radiosensitivity of human squamous carcinoma cell lines is associated with amount of spontaneous DNA strand breaks. Int J Cancer 2001; 96: 43-53.
4. Marini P, Schmid A, Jendrossek V, Faltin H, Daniel PT, Budach W et al. Irradiation specifically sensitises solid tumour cell lines to TRAIL mediated apoptosis. BMC Cancer 2005; 5 : 5 .

5. Mole RH. Whole body irradiation; radiobiology or medicine? Br J Radiol 1953; 26: 234-241.

6. Kingsley DP. An interesting case of possible abscopal effect in malignant melanoma. Br J Radiol 1975; 48: 863-866.

7. Robin HI, AuBuchon J, Varanasi VR, Weinstein AB. The abscopal effect: demonstration in lymphomatous involvement of kidneys. Med Pediatr Oncol 1981; 9: 473-476.

8. Wersall PJ, Blomgren H, Pisa P, Lax I, Kalkner KM, Svedman C. Regression of non-irradiated metastases after extracranial stereotactic radiotherapy in metastatic renal cell carcinoma. Acta Oncol 2006; 45: 493-497.

9. Apetoh L, Ghiringhelli F, Tesniere A, Criollo A, Ortiz C, Lidereau R et al. The interaction between HMGB1 and TLR4 dictates the outcome of anticancer chemotherapy and radiotherapy. Immunol Rev 2007; 220: 47-59.

10. Apetoh L, Ghiringhelli F, Tesniere A, Obeid M, Ortiz C, Criollo A et al. Toll-like receptor 4-dependent contribution of the immune system to anticancer chemotherapy and radiotherapy. Nat Med 2007; 13: 1050-1059.

11. Apetoh L, Tesniere A, Ghiringhelli F, Kroemer G, Zitvogel L. Molecular interactions between dying tumor cells and the innate immune system determine the efficacy of conventional anticancer therapies. Cancer Res 2008; 68: 4026-4030.

12. Kepp O, Galluzzi L, Martins I, Schlemmer F, Adjemian S, Michaud M et al. Molecular determinants of immunogenic cell death elicited by anticancer chemotherapy. Cancer Metastasis Rev 2011; 3: 61-69.

13. Kepp O, Tesniere A, Zitvogel L, Kroemer G. The immunogenicity of tumor cell death. Curr Opin Oncol 2009; 21: 71-76.

14. Tesniere A, Apetoh L, Ghiringhelli F, Joza N, Panaretakis T, Kepp $\mathrm{O}$ et al. Immunogenic cancer cell death: a key-lock paradigm. Curr Opin Immunol 2008; 20: 504-511.

15. Tesniere A, Schlemmer F, Boige V, Kepp O, Martins I, Ghiringhelli F et al. Immunogenic death of colon cancer cells treated with oxaliplatin. Oncogene 2010; 29: 482-491.

16. Fucikova J, Kralikova P, Fialova A, Brtnicky T, Rob L, Bartunkova J et al. Human tumor cells killed by anthracyclines induce a tumor-specific immune response. Cancer Res 2011; 71: 4821-4833.

17. Kroemer G, Zitvogel L. Abscopal but desirable: the contribution of immune responses to the efficacy of radiotherapy. Oncoimmunology 2012; 1: 407-408.

18. Michaud M, Sukkurwala AQ, Martins I, Shen S, Zitvogel L, Kroemer G. Subversion of the chemotherapy-induced anticancer immune response by the ecto-ATPase CD39. Oncoimmunology 2012; 1: 393-395.

19. Ohba K, Omagari K, Nakamura T, Ikuno N, Saeki S, Matsuo I et al. Abscopal regression of hepatocellular carcinoma after radiotherapy for bone metastasis. Gut 1998; 43: 575-577

20. Demaria S, Ng B, Devitt ML, Babb JS, Kawashima N, Liebes $L$ et al. lonizing radiation inhibition of distant untreated tumors (abscopal effect) is immune mediated. Int J Radiat Oncol Biol Phys 2004; 58: 862-870.

21. Hong JH, Chiang CS, Tsao CY, Lin PY, McBride WH, Wu CJ. Rapid induction of cytokine gene expression in the lung after single and fractionated doses of radiation. Int $J$ Radiat Biol 1999; 75: 1421-1427.

22. Postow MA, Callahan MK, Barker CA, Yamada Y, Yuan J, Kitano S et al. Immunologic correlates of the abscopal effect in a patient with melanoma. N Engl J Med 2012; 366: 925-931.

23. McFarland HI, Puig M, Grajkowska LT, Tsuji K, Lee JP, Mason KP et al. Regulatory T cells in gamma irradiation-induced immune suppression. PLoS One 2012; 7: e39092.

24. Mougiakakos D, Johansson CC, Kiessling R. Naturally occurring regulatory $T$ cells show reduced sensitivity toward oxidative stress-induced cell death. Blood 2009; 113: 3542-3545.

25. Mougiakakos D, Johansson CC, Jitschin R, Bottcher M, Kiessling R. Increased thioredoxin1 production in human naturally occurring regulatory $T$ cells confers enhanced tolerance to oxidative stress. Blood 2011; 117: 857-861.

26. Poschke I, Kiessling R. On the armament and appearances of human myeloid-derived suppressor cells. Clin Immunol 2012; 144: 250-268.

27. Suzuki E, Kapoor V, Jassar AS, Kaiser LR, Albelda SM. Gemcitabine selectively eliminates splenic Gr-1 +/CD11b + myeloid suppressor cells in tumor-bearing animals and enhances antitumor immune activity. Clin Cancer Res 2005; 11: 6713-6721.

28. Vincent J, Mignot G, Chalmin F, Ladoire S, Bruchard M, Chevriaux A et al. 5-Fluorouracil selectively kills tumor-associated myeloid-derived suppressor cells resulting in enhanced T cell-dependent antitumor immunity. Cancer Res 2010; 70: 3052-3061.

29. Mizukami Y, Kono K, Daigo Y, Takano A, Tsunoda T, Kawaguchi Y et al. Detection of novel cancer-testis antigen-specific T-cell responses in TIL, regional lymph nodes, and PBL in patients with esophageal squamous cell carcinoma. Cancer Sci 2008; 99: $1448-1454$.

30. Kono K, Mizukami Y, Daigo Y, Takano A, Masuda K, Yoshida K et al. Vaccination with multiple peptides derived from novel cancer-testis antigens can induce specific T-cell responses and clinical responses in advanced esophageal cancer. Cancer Sci 2009; 100: 1502-1509.

31. Kono K, linuma H, Akutsu Y, Tanaka H, Hayashi N, Uchikado Y et al. Multicenter, phase II clinical trial of cancer vaccination for advanced esophageal cancer with three peptides derived from novel cancer-testis antigens. J Transl Med 2012; 10: 141. 
32. Suzuki Y, Mimura K, Yoshimoto Y, Watanabe M, Ohkubo Y, Izawa S et al. Immunogenic tumor cell death induced by chemoradiotherapy in patients with esophageal squamous cell carcinoma. Cancer Res 2012; 72: 3967-3976.

33. Andersson U, Erlandsson-Harris $\mathrm{H}$, Yang H, Tracey KJ. HMGB1 as a DNA-binding cytokine. J Leukoc Biol 2002; 72: 1084-1091.

34. Bell CW, Jiang W, Reich CF 3rd, Pisetsky DS. The extracellular release of HMGB1 during apoptotic cell death. Am J Physiol Cell Physiol 2006; 291: C1318-C1325.

35. Dumitriu IE, Bianchi ME, Bacci M, Manfredi AA, Rovere-Querini P. The secretion of HMGB1 is required for the migration of maturing dendritic cells. J Leukoc Biol 2007; 81: 84-91.

36. Rovere-Querini P, Capobianco A, Scaffidi P, Valentinis B, Catalanotti F, Giazzon M et al. HMGB1 is an endogenous immune adjuvant released by necrotic cells. EMBO Rep 2004; 5: $825-830$.

37. Ivanov S, Dragoi AM, Wang X, Dallacosta C, Louten J, Musco G et al. A novel role for HMGB1 in TLR9-mediated inflammatory responses to CpG-DNA. Blood 2007; 110: 1970-1981.

38. Tian J, Avalos AM, Mao SY, Chen B, Senthil K, Wu H et al. Toll-like receptor 9-dependent activation by DNA-containing immune complexes is mediated by HMGB1 and RAGE. Nat Immunol 2007; 8: 487-496.

39. Chung HW, Lee SG, Kim H, Hong DJ, Chung JB, Stroncek D et al. Serum high mobility group box-1 (HMGB1) is closely associated with the clinical and pathologic features of gastric cancer. J Transl Med 2009; 7: 38

40. Jube S, Rivera ZS, Bianchi ME, Powers A, Wang E, Pagano I et al. Cancer cell secretion of the DAMP protein HMGB1 supports progression in malignant mesothelioma. Cancer Res 2012; 72: 3290-3301.

41. Sims GP, Rowe DC, Rietdijk ST, Herbst R, Coyle AJ. HMGB1 and RAGE in inflammation and cancer. Annu Rev Immunol 2010; 28: 367-388.

42. Fahmueller YN, Nagel D, Hoffmann RT, Tatsch K, Jakobs T, Stieber P et al. Immunogenic cell death biomarkers HMGB1, RAGE, and DNAse indicate response to radioembolization therapy and prognosis in colorectal cancer patients. Int J Cancer 2013; 132: 2349-2358.

43. Chung HW, Lim JB, Jang S, Lee KJ, Park KH, Song SY. Serum high mobility group box-1 is a powerful diagnostic and prognostic biomarker for pancreatic ductal adenocarcinoma. Cancer Sci 2012; 103: 1714-1721.

44. Soldevilla B, Diaz R, Silva J, Campos-Martin Y, Munoz C, Garcia V et al. Prognostic impact of DeltaTAp73 isoform levels and their target genes in colon cancer patients. Clin Cancer Res 2011; 17: 6029-6039.

45. Liu Y, Xie C, Zhang X, Huang D, Zhou X, Tan P et al. Elevated expression of HMGB1 in squamous-cell carcinoma of the head and neck and its clinical significance. Eur $J$ Cancer 2010; 46: 3007-3015.

46. Lee $\mathrm{H}$, Song M, Shin N, Shin $\mathrm{CH}$, Min BS, Kim HS et al. Diagnostic significance of serum HMGB1 in colorectal carcinomas. PLoS One 2012; 7: e34318.

47. Wild CA, Bergmann C, Fritz G, Schuler P, Hoffmann TK, Lotfi R et al. HMGB1 conveys immunosuppressive characteristics on regulatory and conventional T cells. Int Immunol 2012; 24: 485-494.

48. Wild CA, Brandau S, Lotfi R, Mattheis S, Gu X, Lang S et al. HMGB1 is overexpressed in tumor cells and promotes activity of regulatory $T$ cells in patients with head and neck cancer. Oral Oncol 2012; 48: 409-416.

49. Yan W, Chang Y, Liang X, Cardinal JS, Huang H, Thorne SH et al. High-mobility group box 1 activates caspase-1 and promotes hepatocellular carcinoma invasiveness and metastases. Hepatology 2012; 55: 1863-1875.

50. Basu S, Srivastava PK. Calreticulin, a peptide-binding chaperone of the endoplasmic reticulum, elicits tumor- and peptide-specific immunity. J Exp Med 1999; 189: 797-802.

51. Maattanen P, Kozlov G, Gehring K, Thomas DY. ERp57 and PDI: multifunctional protein disulfide isomerases with similar domain architectures but differing substrate-partner associations. Biochem Cell Biol 2006; 84: 881-889.

52. Obeid M, Tesniere A, Ghiringhelli F, Fimia GM, Apetoh L, Perfettini JL et al. Calreticulin exposure dictates the immunogenicity of cancer cell death. Nat Med 2007; 13: 54-61.
53. Zitvogel L, Kepp O, Senovilla L, Menger L, Chaput N, Kroemer G. Immunogenic tumor cell death for optimal anticancer therapy: the calreticulin exposure pathway. Clin Cancer Res 2010; 16: 3100-3104.

54. Michaud M, Martins I, Sukkurwala AQ, Adjemian S, Ma Y, Pellegatti P et al. Autophagy-dependent anticancer immune responses induced by chemotherapeutic agents in mice. Science 2011; 334: 1573-1577.

55. Obeid M, Panaretakis T, Tesniere A, Joza N, Tufi R, Apetoh L et al. Leveraging the immune system during chemotherapy: moving calreticulin to the cell surface converts apoptotic death from "silent" to immunogenic. Cancer Res 2007; 67: 7941-7944.

56. Chiba S, Baghdadi M, Akiba H, Yoshiyama H, Kinoshita I, Dosaka-Akita H et al. Tumor-infiltrating DCs suppress nucleic acid-mediated innate immune responses through interactions between the receptor TIM-3 and the alarmin HMGB1. Nat Immunol 2012; 13 . 832-842.

57. Jinushi M. Regulatory mechanisms of nucleic acid-mediated innate immune responses in the tumor microenvironment. Oncoimmunology 2012; 1: 1632-1634.

58. Tang D, Lotze MT. Tumor immunity times out: TIM-3 and HMGB1. Nat Immunol 2012; 13: 808-810.

59. Kuchroo VK, Dardalhon V, Xiao S, Anderson AC. New roles for TIM family members in immune regulation. Nat Rev Immunol 2008; 8: 577-580.

60. Sanchez-Fueyo A, Tian J, Picarella D, Domenig C, Zheng XX, Sabatos CA et al. Tim-3 inhibits $T$ helper type 1-mediated auto- and alloimmune responses and promotes immunological tolerance. Nat Immunol 2003; 4: 1093-1101.

61. Zhu C, Anderson AC, Schubart A, Xiong H, Imitola J, Khoury SJ et al. The Tim-3 ligand galectin-9 negatively regulates $T$ helper type 1 immunity. Nat Immunol 2005; 6: 1245-1252.

62. Anderson AC, Anderson DE, Bregoli L, Hastings WD, Kassam N, Lei C et al. Promotion of tissue inflammation by the immune receptor Tim-3 expressed on innate immune cells. Science 2007; 318: 1141-1143.

63. Nagahara K, Arikawa T, Oomizu S, Kontani K, Nobumoto A, Tateno H et al. Galectin-9 increases Tim-3 + dendritic cells and CD8 + T cells and enhances antitumor immunity via galectin-9-Tim-3 interactions. J Immunol 2008; 181: 7660-7669.

64. Daly JM, Weintraub FN, Shou J, Rosato EF, Lucia M. Enteral nutrition during multimodality therapy in upper gastrointestinal cancer patients. Ann Surg 1995; 221: 327-338.

65. Takagi K, Yamamori H, Furukawa K, Miyazaki M, Tashiro T. Perioperative supplementation of EPA reduces immunosuppression induced by postoperative chemoradiation therapy in patients with esophageal cancer. Nutrition 2001; 17: 478-479.

66. Igney FH, Krammer PH. Death and anti-death: tumour resistance to apoptosis. Nat Rev Cancer 2002; 2: 277-288.

67. Thompson CB. Apoptosis in the pathogenesis and treatment of disease. Science 1995; 267: 1456-1462.

68. Fahmueller YN, Nagel D, Hoffmann RT, Tatsch K, Jakobs T, Stieber P et al. Immunogenic cell death biomarkers HMGB1, RAGE and DNAse indicate response to radioembolisation therapy and prognosis in colorectal cancer patients. Int $J$ Cancer 2013; 132: 2349-2358.

69. Stoetzer OJ, Fersching DM, Salat C, Steinkohl O, Gabka CJ, Hamann U et al. Circulating immunogenic cell death biomarkers HMGB1 and RAGE in breast cancer patients during neoadjuvant chemotherapy. Tumour Biol 2013; 34: 81-90.

(c) (i) $(-)$ Cell Death and Disease is an open-access journal published by Nature Publishing Group. This work is licensed under a Creative Commons Attribution-NonCommercialNoDerivs 3.0 Unported License. To view a copy of this license, visit http://creativecommons.org/licenses/by-nc-nd/3.0/ 